\title{
Silencio roto (Montxo Armendáriz): imperativos del relato y política de la memoria
}

\section{Vicente Sánchez-Biosca}

Silencio roto (2001), el film de Montxo Armendáriz que se ocupa del maquis, aparece en un momento clave en que los temas de la Guerra Civil española conocen un nuevo auge. Al igual que la exitosa Soldados de Salamina (2002) de David Trueba, muestra un denodado esfuerzo por aportar documentación y ser fiel a un realismo de partida. Armendáriz llevó a su equipo técnico a relacionarse con los supervivientes de la guerrilla antifranquista, del mismo modo que se inspiró en los estudios de historiadores competentes. Sin embargo, las exigencias de una narración dramatizada colisionan con el afán de realismo. Sea como fuera, Silencio roto se prolongará en el documental producido por el mismo director y Puy Oria La guerrilla de la memoria (Javier Corcuera, 2002), de modo harto sintomático, pues revela que para los estándares de nuestro tiempo el soporte documental y el acicate del testimonio vivo se consideran los instrumentos inevitables para interrogar el pasado. El trayecto de Silencio roto a La guerrilla de la memoria es asi revelador de nuestras políticas de la memoria en lo que concierne a la Guerra Civil espaftola. ${ }^{1}$

\section{Guerra Civil y Franquismo al filo del 2000}

En el cine español, la Guerra Civil y sus secuelas fueron siempre un motivo dramáticamente intenso y narrativamente recurrente. Ello no significa que esta predisposición dramática se haya plasmado por igual en todo periodo histórico. Si a lo largo del Franquismo el tema varió según las coyunturas desde la intolerancia militante hasta un tímido intento de integración del enemigo, pasando por la fiebre anticomunista, no es menos cierto que los márgenes de la censura permitieron, por omisión o por laxitud, introducir la figura humana del enemigo. En todo caso, fue la Transición a la democracia, entre 1976 y principios de los años ochenta, el perlodo de mayor volumen de películas y variedad genérica. Desde aquel momento, quizá no ha habido otro periodo tan prolijo en films y variado en temas y subtemas 
como el que se abre a comienzos del tercer milenio desde donde se ha producido el salto a un medio de comunicación más ágil y cercano a la actualidad, a saber: la televisión.

Este hecho revela dos series de cuestiones: en primer lugar, que el estudio de las manifestaciones cinematográficas ha de considerarse en el contexto de coyunturas políticas, culturales y generacionales muy complejas y no en el estrecho marco del cine o de las poéticas de autor; en segundo lugar, que tales coyunturas implican asimismo un tejido no menos denso de diálogos entre distintos medios de comunicación y ámbitos sociales (televisión, cine, publicaciones, revistas, programas radiofónicos, internet, prensa, debates parlamentarios). Pues bien, dada la concentración actual de los medios de comunicación, el fenómeno de la Guerra Civil se ha convertido en una de las industrias culturales más potentes de los últimos años implicando en su entramado publicación de libros, emisión de reportajes televisivos, edición de facsímiles de época y captación de testimonios en distintos soportes sobre la tragedia española de 1936. Soldados de Salamina, la novela que Javier Cercas puso a la venta en marzo de 2001 y que pronto David Trueba adaptó a la pantalla, constituyó un desencadenante, al tiempo, por paradójico que parezca, que una cristalización. (Sánchez-Biosca 2006)

Un renovado interés por el pasado (cuyo síntoma universal es el auge de la novela histórica), un cruce entre investigación (o, en ocasiones, pseudoinvestigación) histórica y creación artística, una atención creciente prestada a los protagonistas de la Guerra Cívil, así como la búsqueda de nudos narrativos candentes (¿nostalgia de la última barbarie espaffola?) en medio de una situación politica y social relativamente estabilizada, confluyen en la conversión de la Guerra Civil y sus consecuencias en el eje de numerosos productos combinados. Este es el contexto en el que surge Silencio roto (M. Ammendáriz, 2001), dedicado a la guerrilla antifranquista, es decir, al maquis. No había sido éste un motivo históricamente muy recurrente. Durante el Franquismo, sólo apuntó en una coyuntura del anticomunismo: Dos caminos (Arturo Ruiz-Castillo, 1953) fue un ejemplo atípico en el que dos soldados republicanos tomaban en el momento de la derrota sendas distintas, una acertada (regresar a España), la otra fatídica (exiliarse, con lo que ello desencadenaba de internamiento en campos y, por último, incorporación a la guerrilla); su amistad no se veía por ello afectada. La paz empieza nunca (León Klimovsky, 1960) consideraba 
la lucha contra el maquis una prolongación de la batalla anticomunista emprendida mucho antes por Franco, como la había considerado precisamente el periodista falangista Emilio Romero, autor de la novela homónima y supervisor del guión. El espiritu de la colmena (Victor Erice, 1973), al borde de la Transición, recreaba un maquisard solitario e indefenso, cruelmente asesinado en medio de la meseta castellana para horror y trauma de una nifia en su proceso de transformación. Pim, pam, pum... ffuego! (Pedro Olea, 1975) evocaba la guerrilla desde el interior de la ciudad. Y fue más tarde cuando Julio Llamazares, autor de la novela Luna de lobos (1985), colaboró en su adaptación por J. Sánchez Valdés en 1986.

\section{Silencio roto como síntoma}

El proceso que condujo a Montxo Armendáriz a realizar Silencio roto es revelador de cuanto acabamos de exponer. Introducido por el actor Carmelo Gómez en el tema de la guerrilla antifranquista, sus primeras lecturas fueron los estudios de Secundino Serrano sobre el maquis en León que cristalizaron en el libro Maquis. Historia de la guerrilla antifranquista (2001). Poco más tarde, trató Armendáriz de llevar a la pantalla la novela Maquis, del valenciano Alfons Cervera (1997), pero su carácter coral planteó problemas al parecer irresolubles al guión. No cejó, pese a todo, el director de documentarse sobre el particular completando su formación con las investigaciones de algunos historiadores de la guerrilla (particularmente, Fernanda Romeu, Justo Vila y Mercedes Yusta) ${ }^{2}$ hasta que el guión de Silencio roto tomó forma. Aclaremos que no nos encontramos ante un proceso corriente de documentación histórica para la producción de un film, sino de algo más significativo: la interrelación entre el cine y el discurso histórico, aunque para tal fin no se juzgó necesaria la figura del asesor histórico, como en los casos anteriormente citados.

Precisamente porque el período que se trataba de llevar a la pantalla era cercano, la documentación visual escasísima (no existen imágenes en movimiento de la guerrilla y apenas algunas fotografias, sobre todo las siniestras que registraba la Guardia Civil de los guerrilleros muertos) y las fuentes orales parte de la llamada historia del tiempo presente, la documentación libresca no bastó ni satisfizo a su autor. A fin de ampliar la información escrita con testimonios directos, buscó el contacto con guerrilleros supervivientes, con mujeres que 
habian servido de puntos de apoyo en los pueblos por los que la guerrilla pasaba y llevó al equipo técnico y artístico de Silencio roto al pueblo conquense de Santa Cruz de Moya, donde se celebraban unos encuentros anuales sobre la guerrilla antifranquista que se han convertido en una auténtica institución. ${ }^{3}$ En su afán por crear un ambiente propicio al realismo y fiel a los testimonios, Armendáriz instaló a su equipo en unos caseríos de la zona de rodaje (el Pirineo navarro) durante las dos semanas previas al inicio del mismo con el propósito de estimular la convivencia y recrear el clima de aislamiento y concentración que consideraba necesario para la interpretación de los actores mientras ultimaba los ensayos.

Estos hechos son de por sí elocuentes del esfuerzo del que surge la película tentativa realista, recuperación histórica libresca, importancia del factor humano en la documentación y búsqueda del discurso testimonial. Todos ellos significativos de la actitud ética de Armendáriz, pero también son síntomas de un tiempo en el que la Guerra Civil española se está convirtiendo, con la inminente desaparición de los últimos testigos y la sed de reportaje de nuestras televisiones, en el período por excelencia de visitación cinematográfica del pasado.

\section{La restricción del punto de vista}

La imagen se abre sobre unos hermosos parajes de las montañas navarras, dominados por la quietud y sin asomo de presencia humana; la niebla penetra en los espesos bosques. De repente, unos disparos y, sin dilación, unas ráfagas de fusil quiebran esa precaria paz. La cámara se eleva hasta filmar el cielo tamizado por la niebla y de ese entorno surge el título. Apenas puede hallarse mejor introito a los sentidos que encierra la expresión 'Silencio roto': la hermosura de un paisaje que guarda en su seno la muerte, el mutismo forzado de los vecinos de un pueblecito, la espera, ora inquieta, ora anhelante, de la fractura violenta; el estallido, por fin, de un enfrentamiento desigual, la represión y el asesinato.

Acto seguido, un autobús local surca una estrecha carretera de montaña para depositar en la plaza de un grupo de casas sin nombre a una muchacha que ronda los 21 años y que responde al nombre de Lucía (Lucía Jiménez). Es el oscuro otoño de 1944 y Lucía regresa a su pueblo natal que abandonó tras el alzamiento militar de julio de 1936 al que siguió una feroz represión que acarreó la muerte de su 
padre, de simpatías republicanas. Toda la galería de personajes introducidos en los primeros compases de la película -Manuel (Juan Diego Botto), Lola (María Botto), Teresa (Mercedes Sampietro), casada con un falangista, don Hilario (Álvaro de Luna), Sebas, el ovejero (Rubén Ochandiano)- están marcados por una herida que se remonta a la guerra y los sume en un silencio opaco; pero muchos de ellos realizarán, también calladamente, su labor de zapa contra el Franquismo en apoyo de los guerrilleros que, pronto lo sabremos, se han instalado en las montañas circundantes. En medio de la tenue alegría que invade estos reencuentros, las miradas se detienen ante la ominosa imagen de dos guardias civiles que descienden del monte, portando, sobre la grupa de un mulo y cubierto con una manta, el cuerpo sin vida de un hombre. El clima para las confidencias, aunque veladas, se ha creado y Lucía se familiariza pronto con la respiración interna y clandestina de los colaboradores de la guerrilla.

El pueblo es, pues, una zona de paso, un umbral atroz: don Hilario fue un maestro republicano que, tras pasar por la cárcel, ha sido recientemente puesto en libertad, pero sigue depurado de su oficio; Manuel, el herrero, tiene a su padre en el maquis y realiza él mismo tareas de enlace con la guerrilla hasta que, perseguido por la Guardia Civil, se ve obligado a echarse al monte e incorporarse a la lucha armada; lo mismo le sucede al ovejero y no otro es el caso de Teresa, quien, casada con un fascista, se agazapa tras su aparente repudio de los idealismos, para favorecer desde su privilegiada posición a los de las montañas. Por su parte, Sole (María Vázquez), la esposa del cabo de la Guardia Civil, aporta el contrapunto humano debido a un enclaustramiento forzoso en el otro bando. Más si esta galería de personajes vive entre el silencio y el terror, dos pilares sustentan las certezas y la voz: uno de ellos es el cuartel de la Guardia Civil, lugar repudiado por casi todos los vecinos, asiento de la represión cruenta y despiadada, de la que tan sólo queda exculpada la frágil Sole, cuya existencia no carece de cierta fatalidad. Desde ese acorazado espacio se ejercerá la violencia y el despotismo, la humillación y la persecucion y cuando la llegada de los guerrilleros torne impotente el destacamento, un nutrido contingente de nuevos guardias venidos de fuera tomarán militarmente el pueblo. El otro pilar es el representado por el espacio incierto de los bosques habitados por los guerrilleros, un lugar que, a diferencia del anterior, mantiene un corredor abierto y en circulación constante, por empatía, con los vecinos del pueblo. 
Otoño de 1944, verano de 1946, inviemo de 1948 son los tres hitos históricos que sirven de escansión a la ficción y entre las acciones que en cada una de ellas se producen median prolongadas elipsis. Si la primera fecha alude a la llegada de Lucía, el verano de 1946 se abrirá con la imupción de los guerrilleros en el pueblo obedeciendo a una operación de invasión de maquisards y toma de treinta pueblos de España y se cerrará, tras las represalias cruentas sobre los familiares y colaboradores de los guerrilleros, con la muerte 'accidental' del padre de Manuel, presumiblemente asesinado por su disconformidad con los dirigentes del maquis, el embarazo de Lucía y su partida a la ciudad. El último episodio transcurre con el nuevo regreso de la muchacha, portando la foto de su hija para mostrarla a un Manuel que se encuentra ya acorralado y desengañado en su escondrijo del bosque. Los tiempos han cambiado, "ahora el pueblo -dice Teresa- es un cementerio", muchos han muerto y la guerrilla, amén de enfrentada entre s1, ha perdido todas sus ilusiones de éxito.

Son éstas acotaciones históricas a un relato que transcurre dentro de las coordenadas de una restricción del saber: el que corresponde al punto de vista de Lucía. Armendáriz se conduce con una indudable honestidad narrativa: la zambullida de esta joven en el mundo rural, la represión y el descubrimiento del papel de la guerrilla en la vida cotidiana, respecto al pasado y respecto a los anhelos de los personajes constituirá el horizonte de conocimiento del film y también la esperanza y la desesperación tendrán en ella su crisol. Ninguna voluntad de ofrecernos, como es habitual en el cine de esos años, una perspectiva a vista de águila, de conjunto y omnisciente, en la que la voz narrativa se funde y confunde con la del historiador. Lo exterior a la reducida comunidad representada (la invasión de maquis por la frontera, la toma de pueblos, incluso la equivoca información que contienen las falsas cartas que recibe Jenaro - Joan Dalmau- de un hijo suyo que lucha en la resistencia francesa) ${ }^{4}$ sólo nos alcanza por medio de alguna noticia de radio, algủn comentario de los personajes, pero sin que la película asuma discurso totalizador alguno.

Ahora bien, si la guerrilla entraña también las ilusiones y desilusiones del pueblo, las opciones forzosas y el ültimo gesto de insubordinación de los antiguos republicanos, también ella es objeto de conflicto entre las directrices políticas emanadas del extranjero y la realidad palpable de quienes exponen su vida en los bosques de Espafia. 
Ninguna idealización se practica: homenaje, quizá, idealización, no. Las represalias y las zonas grises enturbian también al maquis.

\section{Peso del paisaje, convenciones narrativas}

Ciertamente, Armendáriz supo dotar al paisaje agreste de un protagonismo especial y dio al silencio un intenso papel dramático, la latencia de una espera rota por periódicas explosiones. En cualquier caso, el impulso realista se vio obstruido por las convenciones narrativas de las que Armendáriz no supo o no pudo desprenderse: una historia de amor fuertemente codificada en las convenciones filmicas (la que une con todos los énfasis previsibles a Lucía y Manuel), un montaje dramatizado por métodos enfáticos hasta la asfixia (valga como ejemplo la secuencia en la que el teniente de la Guardia Civil obliga al 'Ovejero' a ingerir una botella entera de aceite de ricino en el café del pueblo, subrayando mediante primeros planos y otros de reacción la tensión de la situación vivida por los numerosos asistentes), el uso de una música de sabor a menudo crepuscular e incluso melodramático que realza artificiosamente los hitos del drama conduciendo sin ambigüedad algunas los afectos que el espectador está llamado a sentir en cada momento, la sumisión al star system...

Es muy posible también que los límites de la película de Armendáriz tengan una causa histórica y se desprendan de las exigencias de verosimilitud que los nuevos tiempos imponían a cualquier ficción sobre la Guerra Civil y el Primer Franquismo acometida a comienzos del tercer milenio: un realismo de sesgo testimonial, apoyado o no en documentos de archivo, pero en todo caso sustentado abierta y directamente en la presencia de testigos y víctimas y no sólo inspirado en contactos con los protagonistas del pasado y en una literatura a caballo entre la narración y la historia. En otros términos, un relato clásico y lineal, unos actores de reparto, un montaje dramatizado y una música enfática iban a contracorriente. El mismo Armendáriz debió de percibir esta falla cuando emprendió la producción, junto a Puy Oria, del documental La guerrilla de la memoria (2002), cuya realización fue confiada a Javier Corcuera, el autor de La espalda del mundo (2000). 


\section{De Silencio roto a La guerrilla de la memoria: un itinerario sim- bólico}

El reto de La guerrilla de la memoria consistió en construir un auténtico documental sobre el maquis que partía de un reto: la ausencia de documentos audiovisuales disponibles. Teniendo limitadísimo el material de archivo utilizable, que se reducía a algunas fotos excepcionales y a las de guerrilleros muertos tomadas por la Guardia Civil después de alguna operación de castigo, el interés y la columna vertebral de la película se desplaza a los testimonios de los supervivientes, quienes intentan recrear la clandestina vida de la guerrilla. Resulta muy significativo que el dramatismo de los hechos históricos (las acciones militares, los suministros, la represión, la muerte, etc.) conviva con la evocación por los protagonistas de los días de la montaña: los parajes, la lectura, la organización de escuelas, las ediciones de periódicos, en ocasiones llevando a los testigos a los mismos escenarios en los que vivieron aquella historia que fue lucha política, sufrimiento, pero también una suerte de educación sentimental. La voz de los testigos abre, así, la puerta al conocimiento de una vivencia humana insuficientemente difundida y, paralelamente, la dimensión humana del tiempo compensa la dramatización de los hechos históricos.

Al ser iniciativa de los mismos autores que Silencio roto y, en realidad, su consecuencia, La guerrilla de la memoria es elocuente de un estado verosímil de los films sobre la Guerra Civil y el Primer Franquismo. Si en el preciso año 2001, la obra de Cercas Soldados de Salamina revelaba el interés de dichos temas bajo la fórmula de la novela in fieri, es decir, un estilo heredado de los procedimientos del periodismo actual, que cuenta su proceso mismo de creación; si, apenas unos meses más tarde, su adaptación a la pantalla ponía de relieve la forma postmoderna del pastiche que combina, en caótico amasijo, testimonios orales, documentos audiovisuales, cine familiar, archivos escritos, etc., el itinerario que conduce de Silencio roto a La guerrilla de la memoria ilustra un aspecto no menos sustancial de nuestros tiempos, a saber: el desplazamiento en los códigos de verosimilitud de la representación histórica desde la ficción al ámbito documental, apuntalado por el testimonio filmado. Nos hallamos, pues, ante una política de la memoria. La memoria (y su apoyatura hoy inevitable, el testimonio filmado) constituye el índice por excelencia de credibilidad en nuestra época. Sus abusos, por retomar la célebre denuncia formu- 
lada hace ya años por Tzvetan Todorov (1995), nace de una doble perversión: la presuposición de verdad histórica que se otorga al testimonio sin cotejar con la documentación de archivo y, correlativamente, la coloración afectiva que se impone al documento visual o audiovisual perteneciente al pasado. Pero esto -en realidad de vital importancia para nuestras políticas de la memoria-es ya harina de otro costal.

\section{Notas}

1 El presente texto ha sido concebido en el marco de un proyecto de investigación del Ministerio de Educación y Ciencia 'Función de la imagen mecánica en la memoria de la Guerra Civil española' (HUM2005-02010/ARTE).

2 El libro de conjunto, posterior, de Fernanda Romeu (2002) trata sobre la Agrupación Guerrillera de Levante.

3 Los encuentros de Santa Cruz de Moya se convirtieron en una institución del estudio de la guerrilla y en sus distintas ediciones han colaborado la Universidad de Castilla-La Mancha, el Ayuntamiento de la localidad y multitud de asociaciones, archivos y centros de investigación. Además de un monumento de homenaje al guerrillero y una excursión a un lugar de memoria, La gavilla verde propone unos Senderos de la Memoria por lugares simbólicamente relevantes de la lucha guerrillera. En línea en: Shttp:/www.lagavillaverde.org.>. Hoy los conflictos entre instituciones amenazan su continuidad.

4 Y que, como pronto se revela, murió durante la guerra, si bien la piedad de don Hilario mantiene el recuerdo y la ilusión viva en su extraviado padre escribiendo estas cartas.

\section{Bibliografía}

Cervera, Alfons. 1997. Maquis. Barcelona: Montesinos.

Llamazares, Julio. 1985. Luna de lobos. Barcelona: Seix Barral.

Romeu, Fernanda. 2002. Mós allá de la utopía: Agrupación guerrillera de Levante. Cuenca: Universidad de Castilla-La Mancha.

Sánchez-Biosca, Vicente. 2006. Cine y Guerra Civil espaflola. Del mito a la memoria. Madrid: Alianza.

Serrano, Secundino. 2001. Maquis. Historia de la guerrilla antifranquista. Madrid: Temas de Hoy.

Todorov, Tzvetan. 1995. Les abus de la mémoire. París: Arléa. 


\title{
Miradas sobre pasado y presente en el cine español (1990-2005)
}

\author{
Pietsie Feenstra y Hub. Hermans (ed.)
}

El cine español contemporáneo (1990-2005) dedica mucha atención a la rememoración del pasado (Segunda República, la Guerra Civil, el período franquista,...) y la realidad social (el paro, la violencia doméstica, inmigración, eutanasia,...). Directores renombrados como Pedro Almodóvar, Alejandro Amenábar, Fernando León de Aranoa, Icíar Bollaín, o Isabel Coixet, muestran este interés dentro de sus miradas cinematográficas. La gran popularidad de este cine ha estimulado su migración en pantallas ajenas y dentro de contextos universitarios nacionales e internacionales. Este libro reúne unos veinte artículos, de investigadores americanos y europeos, que ilustran las múltiples tradiciones culturales en vigor dentro de los estudios cinematográficos, y que enfocan al mismo tiempo el tema central del libro: ¿Cómo se puede leer, la mirada de los autores españoles, sobre el pasado y el presente, dentro del contexto de su cine nacional?

\section{ÍNDICE}

\section{Introducción}

Pietsie FEENSTRA y Hub. HERMANS: La migración del cine español

Eduardo RODRIGUEZ MERCHÁN y Gema FERNÁNDEZ-HOYA: La definitiva renovación generacional (1990-2005)

\section{El pasado filmado}

Vicente SÁNCHEZ-BIOSCA: Silencio roto (Montxo Armendáriz): imperativos del relato y política de la memoria

Pilar GARCÍA JIMÉNEZ: Lenguajes de la memoria en El grito del sur: Casas Viejas de Basilio Martín Patino

Bénédicte BRÉMARD: Jaime Camino, Los niños de Rusia (2001), siguiendo el camino de la memoria

Hub. HERMANS: El silencio llevado al cine: Cercas, Trueba y los Soldados de Salamina

Pietsie FEENSTRA: 'Coreografías-monumentales' en La niña de tus ojos (1998) de Fernando Trueba 


\section{El presente filmado}

Ficción: discursos diversos sobre temas sociales

Isabel MAURER QUEIPO: 'La estética de lo híbrido' en Hable con ella de Pedro Almodóvar

Marina DÍAZ LÓPEZ: ¡Viva la diferencia (sexual)! o El otro lado de la cama (Emilio Martínez-Lázaro, 2002)

Verena BERGER: La soledad a través de la cámara: Solas (1999) de Benito Zambrano

María CAMI-VELA: Cineastas españolas que filman en inglés: Isabel Coixet

Lorenzo Javier TORRES HORTELANO: Poniente (2002) de Chus Gutiérrez. 'En España no hay racismo...'

\section{Documentales ficticios}

Román GUBERN: ¡Hay motivo! (2004): un macrotexto de cine militante

Josetxo CERDÁN: Volar sobre el conflicto vasco: La pelota vasca. La piel contra la piedra / Euskal Pilota. Larrua Harriaren Kontra (Julio Medem, 2003)

Pascale THIBAUDEAU: El cine de denuncia social en España: el caso de Te doy mis ojos de Icíar Bollaín

Àngel QUINTANA: Fernando León de Aranoa: Princesas (2005) y el realismo tímido en el cine español

José Luis CASTRO DE PAZ: Mar adentro (Alejandro Amenábar, 2004) y las zozobras del cine español

\section{Sobre los autores}

\section{Colaboran}

